\title{
Workability and Strength Properties of Class C Fly Ash-Based Geopolymer Mortar
}

\author{
Remigildus Cornelis ${ }^{1,{ }^{*}}$, Henricus Priyosulistyo $^{2}$, Iman Satyarno $^{2}$ and Rochmadi ${ }^{3}$ \\ ${ }^{1} \mathrm{Ph} . \mathrm{D}$ Student of the Department of Civil and Environmental Engineering, UGM, Yogyakarta, Indonesia \\ ${ }^{1}$ Staff member of the Department of Science and Engineering, Universitas Nusa Cendana, Kupang, Indonesia \\ ${ }^{2}$ Professor of Department of Civil and Environmental Engineering, UGM, Yogyakarta, Indonesia \\ ${ }^{3}$ Professor ofDepartment of Chemical and Environmental Engineering, UGM, Yogyakarta, Indonesia
}

\begin{abstract}
Fly ash-based geopolymer mortar normally achieves expected properties by heat curing. This becomes one of the obstacles for in-situ applications. The development of high calcium fly ash-based geopolymer mortar, suitable for ambient curing, will gain the applicability of such a material in civil structures. This article reports the results of an experimental study on mortar workability and the increasing of compressive strength of class $\mathrm{C}$ fly ash-based geopolymer mortar created in ambient curing condition. The main synthesis parameters such as alkali to the cementitious mass ratio varied from $30 \%$ to $40 \%$ by an increment of 5\% and absolute volume of paste to absolute volume of voids of the aggregate ratio varied from 1 to 2 by an increment of 0.25 . These parameters were designed to figure out their individual effects on mortar workability and the mechanical properties for the production of geopolymer mortar. The results suggested that the workability of mortar generally increased by using alkali to the cementitious mass ratio. The compressive strength of $60 \mathrm{MPa}$ and the direct tensile strength of $2.8 \mathrm{MPa}$, the ratio of alkali to the cementitious mass of 0.35 and absolute volume of paste to absolute volume of voids of the aggregate ratio was 1.5; it was obtained at ambient temperature after 28 days of age. The results will be useful for developing the knowledge for the use of class $\mathrm{C}$ fly ash in producing geopolymer concrete, which is currently in progress. Hopefully, this contribution of research will improve the applications of such new binding material in the future.
\end{abstract}

\section{Introduction}

In the near future, it is expected that most of the production of construction materials are in accordance with the concept of sustainable development through the utilization of raw materials with lower environmental impact $(1,2)$. So far, it is possible to produce geopolymer pastes that bind fine aggregate to make mortar (3). In fact, fly ash as one of the by-product materials used for geopolymer paste has a double ecological effect that is useful for lower environmental impacts, primarily for to reduce waste and to increase the use of recycled materials. Therefore, geopolymer mortar provides one alternative solution for this objective, making this research to be more interesting and useful to help reducing waste and increasing the use of recycled material.

Fly ash is a by-product of coal combustion product that is the fine particles of fuel that came out from coalfired boilers together with the flue gases. Generally, the components of fly ash vary greatly, but it mostly contains large numbers of silicon dioxide $\left(\mathrm{SiO}_{2}\right)$ (both crystalline and amorphous), aluminum oxide $\left(\mathrm{Al}_{2} \mathrm{O}_{3}\right)$ and calcium oxide $(\mathrm{CaO})$. However, the presence of compounds such as calcium also affects the mechanical properties and the workability of fly ash-based geopolymer (4-9).

It is in line with the Indonesian government policies in the energy sector that allows more coal-burning power plants that build, in turn, hundred millions of tonnes from this by-product such as fly ash that will be produced in Indonesia every year, particularly class $\mathrm{C}$ fly ash. Consequently, it is very necessary to help to manage this by-product or reuse it as useful materials. Thus, the effort to use class $\mathrm{C}$ fly ash waste as a binding material such as cement becomes very helpful, especially in Indonesia. As a locally available material, class $\mathrm{C}$ fly ash-based geopolymers are, therefore, closely related to Indonesia.

\section{Research Significance}

The current study had been done to develop an ambient cured fly ash-based geopolymer mortar for practical utilization in the construction industry. The supplementary investigation was also carried out regarding the influence of the alkali to the cementitious mass ratio and absolute volume of paste to the absolute volume of voids of the aggregate ratio on workability and mechanical behavior of geopolymer mortar. Still, these studies are necessary for locally available class $\mathrm{C}$ fly ash for extensive applications in the construction industry.

\section{Detail of the Experiment}

The current experimental study had been performed in Gadjah Mada University, Yogyakarta, Indonesia. The humidity and the room temperature in the laboratory are

\footnotetext{
*Corresponding author: remi_cor@yahoo.com
} 
around $80 \%$ to $95 \%$ and $26^{\circ} \mathrm{C}$ to $37^{\circ} \mathrm{C}$ respectively. The experimental methodology consisted of two main parts: (1) The preparation of geopolymer mixing, (2) Conducting testing to know the workability, compressive strength, and tensile strength of geopolymer mortar. A flow table test had been done for mortar workability as per relevant ASTMC1437-07(10) codes.

\subsection{Materials}

\subsubsection{Fly Ash}

The fly ash was originally from the power plant in Paiton, East Java, which was available at local market in Yogyakarta, Indonesia. It was used as prime aluminosilicate source material in this experimental study. It is brown in color and the oxides of the fly ash consisted of $40.5 \%$ of $\mathrm{Fe}_{2} \mathrm{O}_{3}, 37.3 \%$ of $\mathrm{SiO}_{2}, 10.7 \%$ of $\mathrm{CaO}$, and $6.37 \%$ of $\mathrm{Al}_{2} \mathrm{O}_{3}$. It was analyzed using X-ray fluorescence (XRF). The cumulative of $\mathrm{SiO}_{2}, \mathrm{Fe}_{2} \mathrm{O}_{3}$ and $\mathrm{Al}_{2} \mathrm{O}_{3}$ compound was greater than $70 \%$ and it may be classified as Class C related to ASTM C618(11). It has bulk specific gravity $\left(G s_{f a}\right.$ in SSD) is 2.86 .

\subsubsection{Alkali solution}

The alkali solution was used for the geopolymerization process. It was prepared by mixing sodium hydroxide $(\mathrm{SH})$ solution and sodium silicate $(\mathrm{SS})$ solution at predetermined proportions. The sodium hydroxide solution was made by mixing $\mathrm{NaOH}$ pellets with aquades in desired molarity $(M)$ and stirred until all of the pellets were really dissolved. The $\mathrm{NaOH}$ pellets with $98 \%$ purity and bulk specific gravity $\left(G s_{s h}\right) 1.52$ are used here. The sodium silicate solution $\left(\mathrm{Na}_{2} \mathrm{SiO}_{3}\right)$ consisted of $7.89 \%$ of $\mathrm{Na}_{2} \mathrm{O}, 19.86 \%$ of $\mathrm{SiO}_{2}$, and $72.25 \%$ of $\mathrm{H}_{2} \mathrm{O}$. It has bulk specific gravity $\left(G s_{s s}\right) 1.59$. Afterward, the alkali solution was set aside for 30 minutes before it was being used. All chemical materials were supplied by PT. Bratachem Bandung.

\subsubsection{Local natural river sand}

The local natural river sand was the source of fine aggregate. The specific gravity, density, and absorption of the natural river sand were calculated based on ASTM C128(12), and the sieve analysis was also conducted according to ASTM C136(13) and ASTM C33-03(14). Table 1 shows the physical properties of the natural river sand with the unit weight of $1531.54\left(\mathrm{~kg} / \mathrm{m}^{3}\right)$, and Figure 1 describes the test results of the sieve analysis and it is showed that the sand is including rather coarse sand.

Table 1. The Physical properties of Local Natural River Sand.

\begin{tabular}{|c|c|c|c|}
\hline Material & $\begin{array}{c}\text { Specific gravity } \\
\text { (SSD) }\end{array}$ & $\begin{array}{c}\text { Absorption } \\
(\%)\end{array}$ & $\begin{array}{c}\text { Fineness } \\
\text { modulus }\end{array}$ \\
\hline $\begin{array}{c}\text { Natural river } \\
\text { sand }\end{array}$ & 2.706 & 2.07 & 3.085 \\
\hline
\end{tabular}

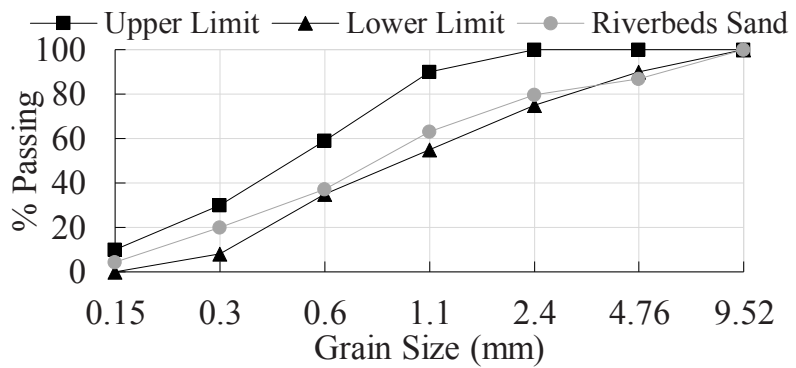

Figure 1. The Local Natural River Sand Sieve Analysis.

\subsection{Mixture Proportion of Geopolymer Mortar}

Recently, there is no standard mix design of geopolymer mortar. In this study, in order to obtain a solid and compact mixture of mortar with the expected rheological and mechanical properties, it is assumed that the volume of the voids of fine aggregate in $1 \mathrm{~m}^{3}$ of fine aggregate is precisely filled by the geopolymer paste. There is also a perfect binding of the geopolymer paste. Thus, the geopolymer mortar mix design is closely related to the parameter $(R m)$ i.e. the ratio between the absolute volume of the paste $\left(V_{p}\right)$ and the absolute volume of the voids of fine aggregate $\left(V v_{r s}\right)$. By knowing the apparent specific gravity $\left(G s_{r s}\right)$ and the unit weight $\left(W s_{r s}\right)$ of the fine aggregate in SSD, the voids ratio of sand could be calculated based on the following equation (15):

$$
V v_{r s}=1-\frac{W s_{r s}}{G s_{r s} \gamma_{w}}
$$

The total component per unit volume of the mortar could be modified as the following equation (16):

$$
\frac{W_{f a}}{G s_{f a} \gamma_{w}}+\frac{W_{s s}}{G s_{s s} \gamma_{w}}+\frac{W_{s h}}{G s_{s h} \gamma_{w}}=R m V v_{r s}
$$

By knowing the mass ratio (R) of sodium silicate $\left(W_{s s}\right)$ to sodium hydroxide $\left(W_{s h}\right)$ and mass ratio $(\mathrm{A})$ of the alkali solution $(W s s+W s h)$ to fly ash $(W f a)$, Eq. (2) could be modified as the following equation:

$$
\frac{W_{f a}}{G s_{f a} \gamma_{w}}+\frac{\left[\frac{A R}{1+R}\right] W_{f a}}{G s_{s s} \gamma_{w}}+\frac{\left[\frac{A}{1+R}\right] W_{f a}}{G s_{s h} \gamma_{w}}=R m V v_{r s}
$$

Where $W_{f a}$ is the weight of fly ash $\left(\mathrm{kg} / \mathrm{m}^{3}\right), W_{s s}$ is the weight of sodium silicate solution $\left(\mathrm{kg} / \mathrm{m}^{3}\right), W_{s h}$ is the weight of sodium hydroxide solution $\left(\mathrm{kg} / \mathrm{m}^{3}\right), G S_{r s}$ is the specific gravity of natural river sand, $G s_{f a}$ is the specific gravity of flyash, $G s_{S S}$ is the specific gravity of sodium silicate solution, $G s_{s h}$ is the specific gravity of sodium hydroxide solution, and $\gamma_{w}$ is the unit weight of water i.e $1000 \mathrm{~kg} / \mathrm{m}^{3}$

In this study, the geopolymer mortar mixtures were varied according to : (i). Mass ratio $(A)(0.3,0.35$ and 0.4$)$; and (ii). Absolute volume ratio $(R m)(1,1.25,1.5$ and 2$)$. Based on our previous study, the Mass ratio $(R)$ was constant at 2 and $\mathrm{NaOH}$ concentration was $10 \mathrm{M}$ for all mixtures per meter cubic as shown in Table $2(9,17,18)$. No superplasticizer used. 
Table 2. The Mixture Proportions of Geopolymer Mortar by weight $\left[\mathrm{kg} / \mathrm{m}^{3}\right]$

\begin{tabular}{|c|c|c|c|c|c|c|c|c|c|}
\hline \multirow[t]{2}{*}{ No } & \multirow[t]{2}{*}{ Sampel } & $\begin{array}{c}\text { Molar ratio } \\
\mathrm{NaOH}\end{array}$ & $\begin{array}{c}\text { Ratio of } \\
\mathrm{Na}_{2} \mathrm{SiO}_{3} / \mathrm{NaOH}\end{array}$ & $\begin{array}{c}\text { Ratio of } \\
\text { Alkaline/Fly ash }\end{array}$ & $\begin{array}{c}\text { Ratio of Vol. Pasta / } \\
\text { Vol. sand cavity }\end{array}$ & $\begin{array}{l}\text { Sand } \\
{[\mathrm{Ws}]}\end{array}$ & $\begin{array}{l}\text { Fly Ash } \\
\text { [Wfa] }\end{array}$ & $\begin{array}{c}\mathrm{Na}_{2} \mathrm{SiO}_{3} \\
{[\mathrm{Wss}]}\end{array}$ & $\begin{array}{l}\mathrm{NaOH} \\
{[\text { Wsh ] }}\end{array}$ \\
\hline & & {$[\mathrm{M}]$} & {$[\mathrm{R}]$} & {$[\mathrm{A}]$} & {$[\mathrm{Rm}]$} & {$\left[\mathrm{kg} / \mathrm{m}^{3}\right]$} & {$\left[\mathrm{kg} / \mathrm{m}^{3}\right]$} & {$\left[\mathrm{kg} / \mathrm{m}^{3}\right]$} & {$\left[\mathrm{kg} / \mathrm{m}^{3}\right]$} \\
\hline 1 & GM10m30A1Rm & 10 & 2 & 30 & 1 & 1531.54 & 801.92 & 160.38 & 80.19 \\
\hline 2 & $\mathrm{GM} 10 \mathrm{~m} 30 \mathrm{Al} .25 \mathrm{Rm}$ & 10 & 2 & 30 & 1.25 & 1237.93 & 1002.4 & 200.48 & 100.24 \\
\hline 3 & GM10m30Al.5Rm & 10 & 2 & 30 & 1.5 & 944.31 & 1202.88 & 240.58 & 120.29 \\
\hline 4 & GM10m30A2Rm & 10 & 2 & 30 & 2 & 357.08 & 1603.84 & 320.77 & 160.385 \\
\hline 5 & GM10m35A1Rm & 10 & 2 & 35 & 1 & 1531.54 & 757.25 & 176.69 & 88.345 \\
\hline 6 & $\mathrm{GM} 10 \mathrm{~m} 35 \mathrm{Al} .25 \mathrm{Rm}$ & 10 & 2 & 35 & 1.25 & 1237.93 & 946.56 & 220.86 & 110.43 \\
\hline 7 & $\mathrm{GM} 10 \mathrm{~m} 35 \mathrm{~A} 1.5 \mathrm{Rm}$ & 10 & 2 & 35 & 1.5 & 944.31 & 1135.87 & 265.04 & 132.52 \\
\hline 8 & GM10m35A2Rm & 10 & 2 & 35 & 2 & 357.08 & 1514.49 & 353.38 & 176.69 \\
\hline 9 & GM10m40A1Rm & 10 & 2 & 40 & 1 & 1531.54 & 717.29 & 191.28 & 95.64 \\
\hline 10 & $\mathrm{GM} 10 \mathrm{~m} 40 \mathrm{Al} .25 \mathrm{Rm}$ & 10 & 2 & 40 & 1.25 & 1237.93 & 896.61 & 239.1 & 119.55 \\
\hline 11 & GM10m40Al.5Rm & 10 & 2 & 40 & 1.5 & 944.31 & 1075.93 & 286.92 & 143.46 \\
\hline 12 & GM10m40A2Rm & 10 & 2 & 40 & 2 & 357.08 & 1434.58 & 382.55 & 191.275 \\
\hline
\end{tabular}

\subsection{Preparation, mixing and curing}

In general, the preparation of geopolymer mixture consisted of two parts: preliminaries of the alkaline solution and final mixing of all constituents. The alkaline solution was provided about 30 minutes before mixing. The procedure started by mixing sodium silicate solution and sodium hydroxide solution based on the specified quantity and it was set aside in the room temperature to cool down.

First of all, the fly ash was mixed thoroughly in Hobart mixture using $140 \mathrm{rpm}$ of speed for 1 minute before adding the alkaline solution as described in ASTM C305(19). The mixed alkaline solution was then added gradually. The mixing process was continued for 5 minutes and then the sand was added gradually. The mixing was continued for another 10 minutes until a homogenous mixture was obtained. The fresh mortar was then it cast in a conical mold of flow table apparatus and ready for testing of flow tests. The fresh mixture was also cast in briquette mold as ASTM C307-03(20) standard for the tensile strength test. For the compressive strength test, the novel mixture was cast in cube molds $(50 \times 50 \times 50$ $\mathrm{mm} 3$ ) into two layers. Each layer was vibrated on the shaking table for 30 seconds to obtain good compaction. The cube molds were made of acrylic and coated using Vaseline beforehand.

The specimens of tensile strength test and compressive strength test were then wrapped with a vinyl sheet and it was cured at room temperature with a relative humidity of $95 \%$. They were removed from the molds after 24 hours of casting and stored at room temperature by covering the exposed surface with a vinyl sheet until it was tested to

The results of workability in terms of flow and effect of alkali to the cementitious mass ratio $(A)$ and absolute volume of paste to absolute volume of voids of the ensure steady surroundings for all specimens rather than the modifiable ambient condition. Each variable had three specimens.

\subsection{Flow test, compressive strength test, and direct tensile strength test.}

The flow of geopolymer mortar was measured using the flow table apparatus according to ASTM C1437-07(10) standard. The flow test was conducted as soon as the mixing of geopolymer mortar in Hobart mixer had been finished. The flow of the mix was set by measuring the diameter of mortar flow on flow table along the four lines scribed in the table top using caliper after 25 number of jolting respectively as stated in the standard. The minimum flow diameter of $110 \pm 5 \%$ was set as a boundary so that the geopolymer mortar could be easily placed and cast in the mold.

A standard test of ASTM C307-03(20) was used to determine the tensile strength of geopolymer mortar using briquette specimens. The tensile strength test was then conducted at the age of 28 days, using ELE $8 \mathrm{kN}$ tensile strength machine loaded at a rate of $5 \mathrm{~mm} / \mathrm{min}$. Three specimens were made for each variable.

ASTM C109/C109M - 16a(21) as a standard test method was used to determine the compressive strength of geopolymer mortar cube specimens. Compressive strength test was conducted at the age of $3,7,28$, and 56 days with cube specimens loaded at a rate of $1.67 \mathrm{kN} / \mathrm{s}$. The test was done by using Avery Dennison $20 \mathrm{kN}$ compressive strength test machine.

\section{Results and Discussions}

aggregate ratio $(R m)$ on compressive strength of geopolymer mortar and tensile strength are presented in the following sections. 


\subsection{Flow Measurement in Geopolymer Mortar}

Figure 2 shows the photographs of mortar spread after 25 drops for all the geopolymer mortar mixtures. It is found that the flow diameter is increased as the ratio of $\mathrm{Rm}$ and alkaline concentration $(A)$ is increasing. This is also indicated that the mix was more viscous and flowable. The effect of alkali to the cementitious mass ratio $(A)$ and absolute volume of paste to absolute volume of voids of the aggregate ratio $(\mathrm{Rm})$ on the flow are presented in Table 3.

Table 3. The Flow Properties of Geopolymer Mortar

\begin{tabular}{|c|c|c|c|c|c|}
\hline No & $\begin{array}{c}\text { ID } \\
\text { Sample }\end{array}$ & Sampel & $\begin{array}{c}\text { Ratio of } \\
\text { Vol. pasta/ Vol. Sand Voids } \\
{[\mathrm{Rm}]}\end{array}$ & $\begin{array}{c}\text { Mortar } \\
\text { Flow } \\
(\%)\end{array}$ & $\begin{array}{l}\text { Ratio of } \\
\text { Fa/Sand }\end{array}$ \\
\hline 1 & MG1 & MG10m30A1Rm & 1 & 28 & 0.52 \\
\hline 2 & MG2 & $\mathrm{M} 10 \mathrm{~m} 30 \mathrm{~A} 1.25 \mathrm{Rm}$ & 1.25 & 62.8 & 0.81 \\
\hline 3 & MG3 & $\mathrm{M} 10 \mathrm{~m} 30 \mathrm{~A} 1.5 \mathrm{Rm}$ & 1.5 & 84.5 & 1.27 \\
\hline 4 & MG4 & $\mathrm{M} 10 \mathrm{~m} 30 \mathrm{~A} 2 \mathrm{Rm}$ & 2 & 109 & 4.44 \\
\hline 5 & MG5 & MG10m35A1Rm & 1 & 49.5 & 0.49 \\
\hline 6 & MG6 & $\mathrm{M} 10 \mathrm{~m} 35 \mathrm{~A} 1.25 \mathrm{Rm}$ & 1.25 & 67.5 & 0.76 \\
\hline 7 & MG7 & $\mathrm{M} 10 \mathrm{~m} 35 \mathrm{~A} 1.5 \mathrm{Rm}$ & 1.5 & 105.5 & 1.20 \\
\hline 8 & MG8 & $\mathrm{M} 10 \mathrm{~m} 35 \mathrm{~A} 2 \mathrm{Rm}$ & 2 & 127 & 4.20 \\
\hline 9 & MG9 & MG10m40A1Rm & 1 & 62.8 & 0.47 \\
\hline 10 & MG10 & $\mathrm{M} 10 \mathrm{~m} 40 \mathrm{~A} 1.25 \mathrm{Rm}$ & 1.25 & 103 & 0.72 \\
\hline 11 & MG11 & $\mathrm{M} 10 \mathrm{~m} 40 \mathrm{~A} 1.5 \mathrm{Rm}$ & 1.5 & 128 & 1.14 \\
\hline 12 & MG12 & $\mathrm{M} 10 \mathrm{~m} 40 \mathrm{~A} 2 \mathrm{Rm}$ & 2 & 139 & 3.98 \\
\hline
\end{tabular}
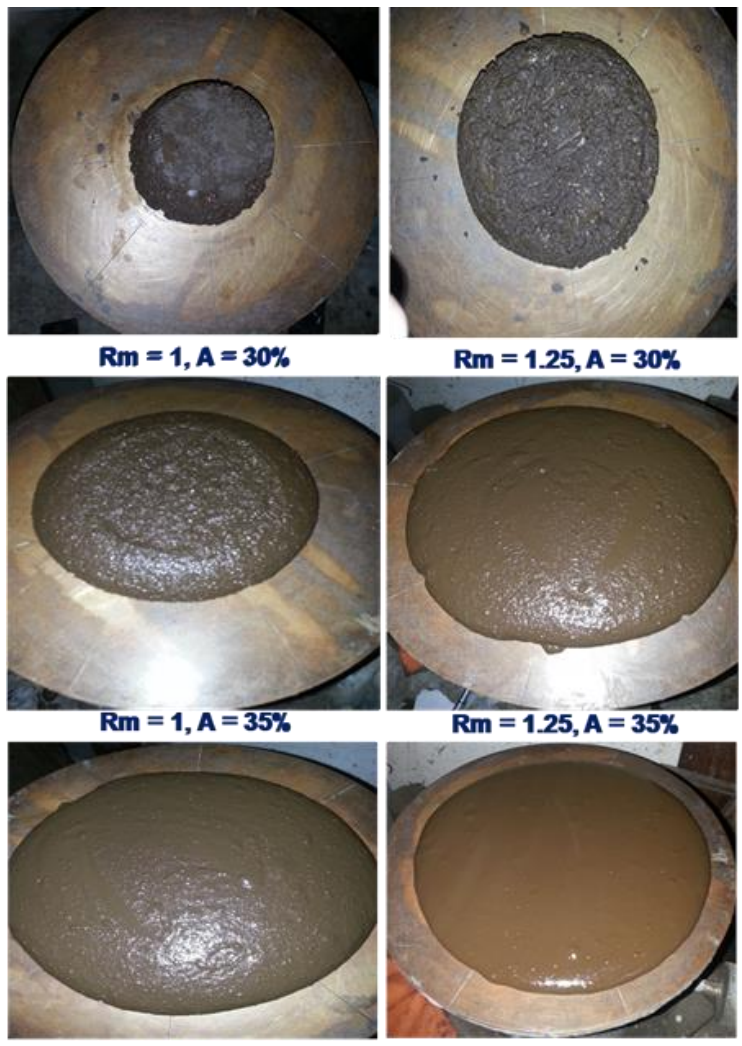

$\mathrm{Rm}=1, \mathrm{~A}=40 \%$
$R m=1.25, A=30 \%$

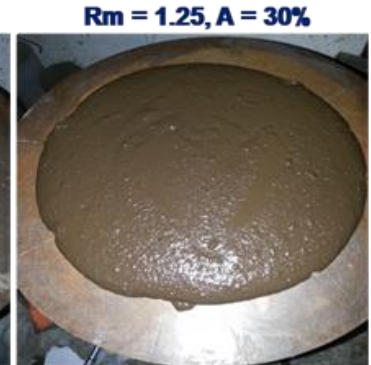

$R m=1.25, A=35 \%$

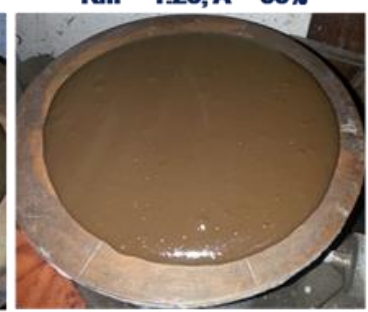

$\mathrm{Rm}=1.25, \mathrm{~A}=40 \%$

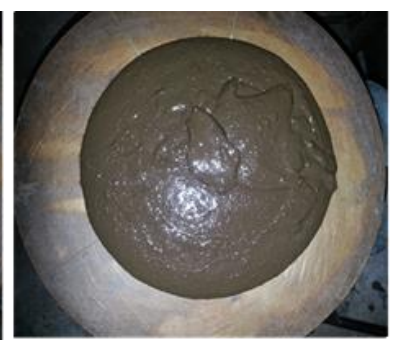

$\operatorname{Rm}=1.5, A=30 \%$

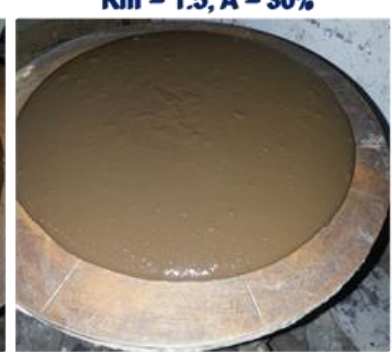

$\operatorname{Rm}=1.5, A=35 \%$

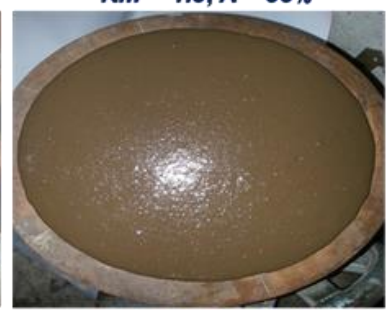

$\mathrm{Rm}=1.5, \mathrm{~A}=40 \%$

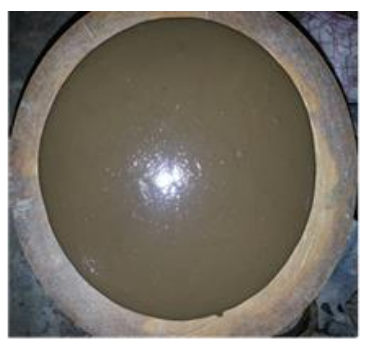

$\mathbf{R m}=\mathbf{2 . 0}, \mathbf{A}=\mathbf{3 0} \%$

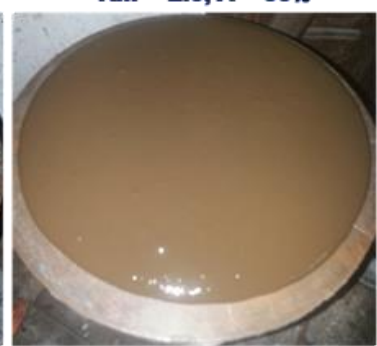

$\operatorname{Rm}=2.0, A=35 \%$

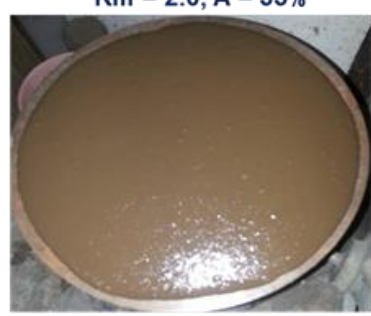

$\mathrm{Rm}=2.0, A=40 \%$

Figure 2. The Effect of alkali to the cementitious mass ratio $(A)$ and absolute volume of paste to absolute volume of voids of the aggregate ratio $(\mathrm{Rm})$ on the geopolymer mortar flow. 


\subsection{Compressive Strength of Geopolymer Mortar}

It is observed that the compressive strength of geopolymer mortar increases with the age as expected in all mixtures. The same trend has been observed for all mixtures with high concentrated alkali as indicated in Figure 3 through 6 . The highest mortar compressive strength of $60 \mathrm{MPa}$ at the age of 28 days was achieved when the alkali content (A) was $35 \%$ and the $R m$ of 1.5 . This increases continuously until the age of 56 days although the increasing trend is not similar for all mixes.

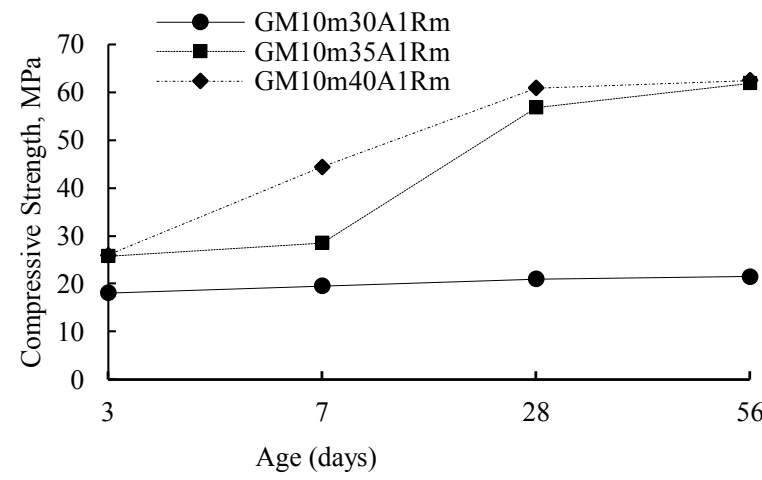

Figure 3. The Effect of alkali to the cementitious mass ratio $(A)$ on compressive strength at $R m=1$

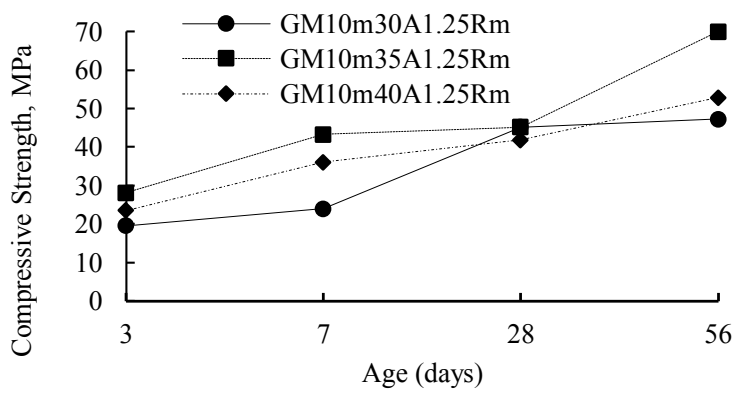

Figure 4. The Effect of alkali to the cementitious mass ratio $(A)$ on compressive strength at $R m=1.25$

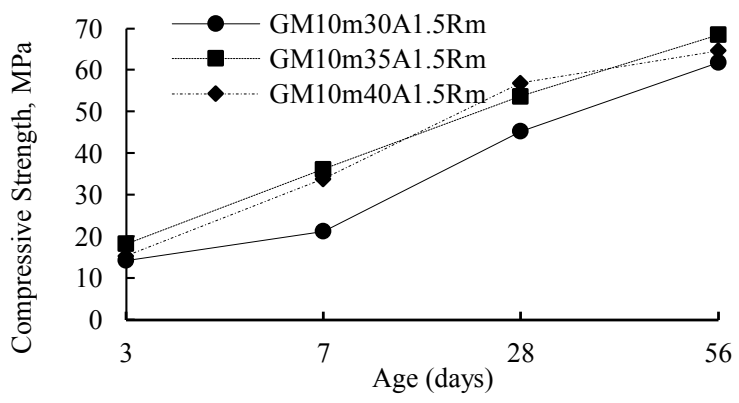

Figure 5. The Effect of alkali to the cementitious mass ratio $(A)$ on compressive strength at $R m=1.5$

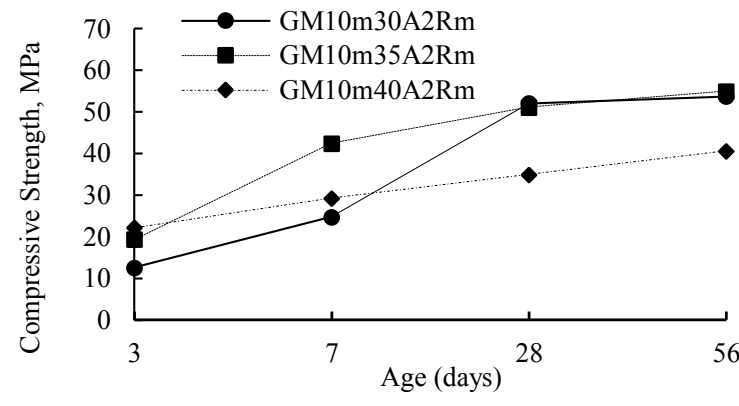

Figure 6. The Effect of alkali to the cementitious mass ratio $(A)$ on compressive strength at $R m=2$

The similar trend is also shown in Figure 7 through Figure 9 where the highest mortar compressive strength was $60 \mathrm{Mpa}$ at the age of 28 days and it tends to increase after the age of 28 days. This result will be the basis for designing a mixture of geopolymer concrete on the next research.

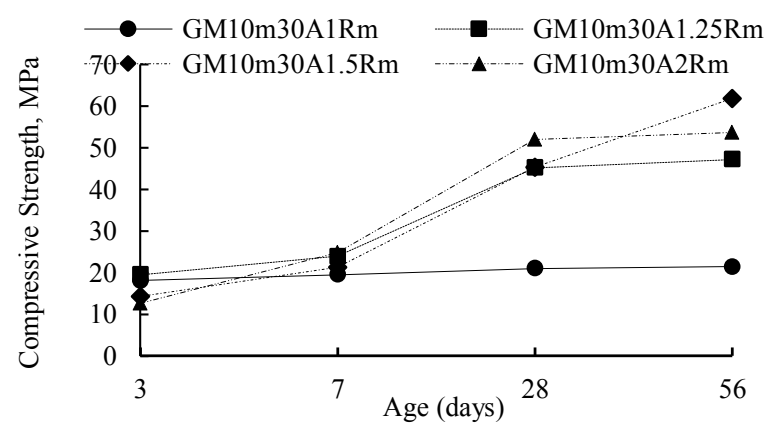

Figure 7. The Effect of absolute volume ratio $(R m)$ of paste to the voids of aggregate on compressive strengthat $\mathrm{A}=30 \%$

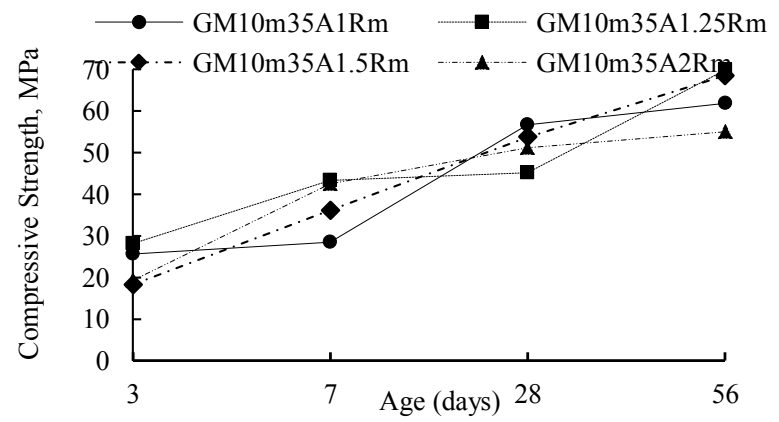

Figure 8. The Effect of absolute volume ratio $(R m)$ of paste to the voids of aggregate on compressive strength at $\mathrm{A}=35 \%$ 


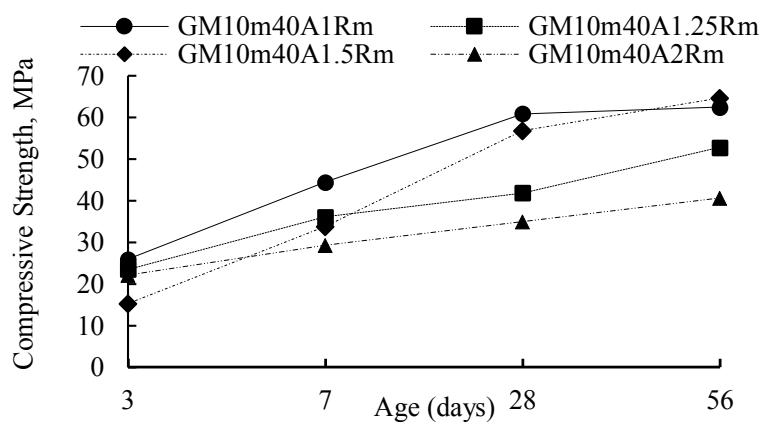

Figure 9. The Effect of absolute volume ratio $(\mathrm{Rm})$ of paste to voids of the aggregate on compressive strength at $\mathrm{A}=40 \%$

\subsection{Conclusions}

The current experimental study conducted at room temperature shows that the workability of fly ash-based geopolymer mortar is increased as the increasing ratio of $A$ and $R m$. But the increase in the tensile strength and the compressive strength is not in line with the increasing ratio of $A$ and $R m$. In general, the highest tensile strength of $2.8 \mathrm{MPa}$ can be obtained if $R m$ ratio is 1.5 . In general, this trend is almost similar to an increase in the compressive strength of high calcium fly ash-based geopolymer mortar. The compressive strength of $60 \mathrm{MPa}$ and the direct tensile strength of $2.8 \mathrm{MPa}$ are obtained here and for alkali to the cementitious ratio is 0.35 ; meanwhile, absolute volume of geopolymer paste to the absolute volume of the voids of the fine aggregate ratio is 1.5 after 28 days of age. Alkaline to fly ash mass ratio and the absolute volume of paste to the absolute volume of the voids of the fine aggregate ratio $(A)$ have a major role in getting maximum compressive strength and tensile strength after 28 days, and so does the workability of fly ash-based geopolymer mortar.

\section{Acknowledgment}

The author would like to express gratitude to the Government of Indonesia, the Minister of Research, Technology and Higher Education that had given financial support for this research.

\section{References}

1. Davidovits J. Global Warming Impact on the Cement and Aggregates Industries. World Resour Rev. 6(2):263-78(1994).

2. Penttala V. Concrete and Sustainable Development. ACI Mater J. 94(94):409-16(1998).

3. Kotwal AR, Kim YJ, $\mathrm{Hu}$ J, Sriraman V. Characterization and Early Age Physical Properties of Ambient Cured Geopolymer Mortar Based on Class C Fly Ash. Int J Concr Struct Mater. 9(1):3543(2015).

4. Temuujin J, Riessen A Van, Williams R. Influence of calcium compounds on the mechanical properties of fly ash geopolymer pastes. J Hazard Mater.
167(167):82-8(2009).

5. Bhowmick A, Ghosh S. Effect of synthesizing parameters on workability and compressive strength of Fly ash based Geopolymer mortar. Int J Civ Struct Eng. 3(1):168-77(2012).

6. Li X, Ma X, Zhang S, Zheng E. Mechanical Properties and Microstructure of Class C Fly AshBased Geopolymer Paste and Mortar. Materials (Basel). :1485-95(2013).

7. Hardjito D, Cheak CC, Ho C, Ing L. Strength and Setting Times of Low Calcium Fly Ash-based Geopolymer Mortar. Mod Appl Sci. 2(1990):311(2008).

8. Chindaprasirt P, Chareerat T, Sirivivatnanon V. Workability and strength of coarse high calcium fly ash geopolymer. Cem Concr Compos. 29:2249(2007).

9. Mustafa AM, Bakri A, Kamarudin H, Bnhussain M, Rafiza AR, Zarina Y. Effect of $\mathrm{Na} 2 \mathrm{SiO} 3 / \mathrm{NaOH}$ Ratios and $\mathrm{NaOH}$ Molarities on Compressive Strength of Fly-Ash-Based Geopolymer. ACI Mater J. 109(109):503-8(2013).

10. ASTM C1437-07. Standard Test Method for Flow of Hydraulic Cement Mortar 1. :6-7(2009).

11. ASTM C618-12a. Standard Specification for Coal Fly Ash and Raw or Calcined Natural Pozzolan for Use. :5-9(2014).

12. ASTM C128-01. Standard Test Method for Density , Relative Density ( Specific Gravity), and Absorption. :1-6(2003).

13. ASTM C136-96a. Sieve Analysis of Fine and Coarse Aggregates. :32-6(2007).

14. ASTM C33-03. Standard Specification for Concrete Aggregates. 04(2001).

15. Neville AM. Properties of concrete Fourth and Final Edition, 860, (2004).

16. Satyarno I, Solehudin AP, Meyarto C, Hadiyatmoko D, Muhammad P, Afnana R. Practical method for mix design of cement-based grout. Procedia Eng. 95(Scescm):356-65(2014).

17. Cornelis $\mathrm{R}$, Priyosulistyo $\mathrm{H}$, Satyarno I. The Investigation on Setting Time and Strength of High Calcium Fly Ash Based Geopolymer. Appl Mech Mater. 881:158-64(2018).

18. Kaur M, Singh J, Kaur M. Synthesis offl y ash based geopolymer mortar considering different concentrations and combinations of alkaline activator solution. Ceram Int. 44(2):1534-7(2018).

19. ASTM C305-06. Standard Practice for Mechanical Mixing of Hydraulic Cement Pastes and Mortars. :6-8(2009).

20. ASTM C307-03. Standard Test Method for Tensile Strength of Chemical-Resistant Mortar, Grouts , and Monolithic Surfacings. :1-4.

21. ASTM C109. Standard Test Method for Compressive Strength of Hydraulic Cement Mortars. 04:1-6(2000). 